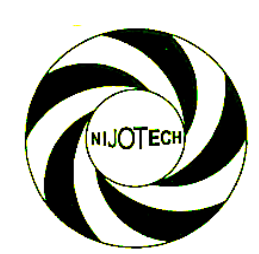

Nigerian Journal of Technology (NIJOTECH)

Vol. 37, No. 1, January 2018, pp. 44 - 52

Copyright@ Faculty of Engineering, University of Nigeria, Nsukka

Print ISSN: 0331-8443, Electronic ISSN: 2467-8821

www.nijotech.com

http://dx.doi.org/10.4314/njt.v37i1.6

\title{
ASSESSMENT OF BUILDING MAINTENANCE IN NIGERIAN UNIVERSITY SYSTEM: A CASE STUDY OF UNIVERSITY OF NIGERIA, NSUKKA
}

\author{
0. O. Ugwu ${ }^{1}$, C. C. Okafor ${ }^{2, *}$ and C. U. Nwoji ${ }^{3}$ \\ 1 Department of Civil EngineEring, Federal University, Ndufo Alike, IKWo, Ebonyi State. NiGERIA. \\ 2,3 DePartment of Civil EngineERING, UNiversity of Nigeria, NSUKKA, ENUGu STATE, NiGERIA. \\ Email addresses: ${ }^{1}$ onuegbu.ugwu@funai.edu.ng, ${ }^{2}$ chigozie.okafor@unn.edu.ng, \\ 3clifford.nwoji@unn.edu.ng
}

\begin{abstract}
Building maintenance involves preserving a building so that it can retain its economic value and durability. Maintenance is a very important aspect of facilities management that requires planning, because lack of maintenance leads to serious economic loss. This research work was carried out to access the current state of maintenance of public buildings in public institutions in Nigeria using the University of Nigeria, Nsukka as a case study. It also proffers solutions to maintenance problems. The field investigation focused on staff residential houses, students' hostels, offices and classrooms. Questionnaires were used to collate data/information on 500 residential apartments, offices and a total of 260 hostel rooms were examined. The results were analyzed statistically. The results show that about $80 \%$ of the buildings within the University require immediate maintenance. Maintenance works are also needed at the staff residential buildings, students' hostels, offices and classrooms. They are also needed in the plumbing works, bathrooms, toilets, doors, windows, the painting, walls, floors, roofs and electrical installations of the buildings. $74.60 \%$ of the residential buildings need roof maintenance, $57.30 \%$ need floor maintenance, $60 \%$ need wall maintenance, $71.30 \%$ need re-painting, and $68.60 \%$ need window maintenance. In the students hostels, $61.70 \%$ of the hostels need door maintenance, $59.50 \%$ need to have their toilet facilities maintained while $72.40 \%$ of the hostels need to have their plumbing works maintained. It is concluded that lack of maintenance policy and funding is the major cause of public building deterioration in University of Nigeria, Nsukka. It is recommended that a holistic maintenance framework should be adopted in line with International best practices in developed countries. In addition, the University should adopt preventive maintenance policy by employing outsourcing maintenance services. The University should also introduce the use of one stop shop maintenance services including the use of information and communication technology.
\end{abstract}

Keywords: Infrastructure maintenance, University system, sustainable building, maintenance culture

\section{INTRODUCTION}

Infrastructural development with well planned maintenance is one of major characteristics of a developed nation. That is why in many developed nations there is a huge presence of several well maintained infrastructures like sky scrapers, tall buildings etc. Infrastructural development and maintenance plays a great role in the socio-economic growth of a nation. Many developed nations invest on infrastructure and depend on it as a source of revenue for their economy. Hence they take maintenance of these infrastructures seriously. Countries like Dubai use infrastructure to attract tourists to their nation and this in turn yield revenue for the country [1]. The
United Kingdom, Canada, United States of America, Australia, New Zealand, South Africa, Germany, France, Japan, China, Hong Kong have many developed educational institutions with adequate infrastructure which is one of the reasons why many Nigerians troop into these countries, spend a lot of money to acquire education [1]. This in turn generates huge revenue for these countries. However routine infrastructural maintenance has been an Achilles in many Nigerian public institutions due to poor funding, misuse of facility by occupants, bribery and corruption etc. [2]. Construction projects in Nigeria are worth billions of Naira. It is of great importance that construction management practices is given great attention [4]

* Corresponding author, tel: +234-703-872-3013 
otherwise, it will negatively affect the management of the infrastructure. Public buildings are allowed to dilapidate to unusable levels before maintenance plans are made to preserve its economic value and durability. Sometimes such buildings are left without any form of maintenance for a long time and these leads to total overhaul and reconstruction of the previously constructed project, resulting in a serious economic waste [1]. According to [5], many institutions carry out infrastructure development through PPP but measurable indicators to success or otherwise do not exist. Maintenance can be defined as every action taken to preserve an infrastructure in its original state so that it will retain its economic value and durability [1]. According to [3], there are two types of maintenance, the planned and unplanned maintenance.

Planned Maintenance consists of preventive maintenance, corrective/emergence maintenance. Under preventive maintenance we have scheduled maintenance and conditioned maintenance. However, unplanned maintenance consists of corrective/emergence maintenance.

In this research work, public buildings to be investigated are the staff residential buildings, student's hostels, classrooms and offices in the University of Nigeria, Nsukka.

\subsection{Statement of Problem}

Erecting infrastructure without a functional maintenance plan or policy for it poses a great danger for the occupant and leads to serious economic loss. According to previous studies on infrastructural maintenance, many infrastructural facilities in public institutions in Nigeria are inadequately maintained. The few that are maintained are allowed to dilapidate completely without any sustainable maintenance plan. Consequent upon this, many infrastructures in public institutions are fast losing their economic value and at the same time putting the life of the occupants in danger. In University of Nigeria, Nsukka, there seems that infrastructural maintenance plan is not in place, also the existing public infrastructural buildings have been dilapidating at a rather fast rate. Such that if no infrastructural maintenance scheme or plan is developed and implemented the University will soon suffer a huge disastrous infrastructural damage. This research therefore will access the dilapidation of these infrastructural facilities. It is hoped that from this study, an infrastructural building maintenance plan will be developed.

\subsection{Objectives of the Study}

The main aim:

i. The aim of this research is to investigate the current state of public buildings within the University of Nigeria, Nsukka.

The specific aims:

ii. To assess the current maintenance practices in Nigeria.

iii. To develop a framework for building maintenance in Nigeria.

iv. To make intelligent suggestions, contributions and recommendations towards the adoption of effective maintenance framework that would address the building maintenance problems in University of Nigeria, Nsukka.

v. To generate reserved data/ records for future maintenance investigations.

\subsection{Justification of the Study}

This research will contribute to knowledge and theory of sustainable maintenance of infrastructure. It will also investigate factors that negatively affect maintenance of public buildings and proffer solutions to the problems. This research will also assist authorities of public institutions in Nigeria to know the current state of their structures and dangers of using deteriorated and badly damaged facilities.

The importance of maintaining good health and safety in relation to good building maintenance practices will also be captured in this research work.

\section{RESEARCH METHODOLOGY}

There is paucity of data and information on infrastructure maintenance. This results from dearth of maintenance culture and policy, which is common in most developing countries. In order to address the associated challenges resulting from data paucity, the research adopted a hybrid method that include: questionnaire survey, structured interview, and case study projects. Both quantitative and qualitative data were collected, and the quantitative data was analyzed using statistical methods. The ensuing sections discus various components of the research method.

In order to situate this study in a practical context, the study was conducted on buildings in a university campus. The case study projects investigated include; Residential Building (Staff quarters), Offices, Hostels and Classrooms. The next section discusses various components of the research in detail. 


\subsection{Questionnaire Design}

The design of questionnaire as research instrument is a very critical component of any research. The questionnaire design in this research was carried out to ensure that appropriate constructs (variables) that define the scope (breadth and depth) of research were captured. The constructs include: demographic data on respondents, various variables that cumulatively define different aspects of maintenance as they affect structural health of buildings and impact on sustainable use of buildings in Nigeria and beyond. Other subsections of the questionnaire elicited data/information on maintenance of building by parts in appropriate levels of details. Structured open-ended questions were designed and included to elicit responses from respondents during interviews. The questionnaire was divided into two main sections.

\subsubsection{Questionnaire Survey}

Survey is a systematic method of gathering information from a target population. The information gathered from surveys can be analyzed statistically to obtain relevant results which give answer to research question.

In this research, over 500 questionnaires were distributed among staff and students of the university and 378 questionnaires were returned for analysis. This represents a response rate of $75.6 \%$.

\subsubsection{Structured Interview}

A Structured interview was used to obtain critical information from the respondents. The respondents explained the role they play in the maintenance of the buildings which they occupy. The respondents also explained how the University's maintenance policy affects them and how effective it has been.

Information on how much the respondents spend on self-maintenance of the buildings which they occupy and how much they pay on rent were also elicited. The interview schedule questionnaire was also sent out to the Works Services Department of the University and was used as case study. The Works Services Department is a unit responsible for the maintenance of every infrastructure owned by the University. The Works Services Department has a Director who controls the affair of the department. The Works Services Department is further divided into 10 different units namely: Utility, Electrical, Academic and Public Building, Hostels and Refectory, Mechanical, North Quarters, South Quarters, Estate, Accommodation, Personnel. Each unit has a head, thus questionnaires were distributed to the heads of different units to obtain several information as they relate to the effectiveness of the University maintenance policy. These include information on frequency of maintenance operations among others.

\subsection{Qualitative-Quantitative Data Analysis - the Likert Scale}

The Likert Scale was used to transform some qualitative responses into quantitative data analysis. Thereafter, basic descriptive statistics such as Mean, median, frequency and percentages were used in the data analysis. As an illustration, factors that affect building maintenance in Nigeria were identified and listed in the question. Respondents were required to rate the significance of various problems as they impact sustainable maintenance, on a Likert Scale of $1-5$, where:

1 - Not significant at all, 2 - Little significance, 3 Average significance, 4 - Significant, and 5 - Very significant. Thus any factor that scores less than 23 on the Likert scale is deemed not to be significant to an average level (See the appendix).

Table 1: Responses from Staff and Students

\begin{tabular}{llcccc}
\hline \multirow{2}{*}{ S/N } & \multicolumn{1}{c}{ Problems } & \multicolumn{2}{c}{ Staff } & \multicolumn{2}{c}{ Students } \\
\cline { 3 - 5 } & & Mean (SD) & Rank & Mean (SD) & Rank \\
\hline 1. & Lack of maintenance policy. & $4.43(1.06)$ & 1 & $4.06(1.22$ & 1 \\
2. & Inadequate provision of funds for maintenance. & $4.37(1.13)$ & 2 & $3.96(1.18)$ & 3 \\
3. & Lack of timely response to maintenance request. & $4.23(1.05)$ & 3 & $3.54(1.32)$ & 8 \\
4. & Poor maintenance work done by the maintenance unit of the & $3.68(1.33)$ & 4 & $3.72(1.25)$ & 7 \\
5. & institution. & $3.67(1.33)$ & 5 & $3.98(1.15)$ & 2 \\
6. & Corruption. & $3.27(1.36)$ & 6 & $3.79(1.24)$ & 6 \\
7. & engineer. & $2.97(1.35)$ & 7 & $3.91(1.26)$ & 4 \\
8. & Chisuse of facilities by occupants. & $2.87(1.49)$ & 8 & $3.82(1.17)$ & 5 \\
9. & Over crowding. & $2.60(1.36)$ & 9 & $3.33(1.35)$ & 9 \\
10. & Poor architectural/structural design. & $2.37(1.31)$ & 10 & $3.32(1.40)$ & 10 \\
\hline
\end{tabular}




\section{RESULTS AND DISCUSSION}

Table 1 shows the results from analysis of responses from both staff and students.

1. Lack of maintenance policy: This problem was ranked No 1 by both staff and students with a mean of 4.43 and 4.06 respectively. This shows that both staff and students believe that the University of Nigeria, Nsukka does not have a well drafted maintenance policy.

2. Inadequate provision of funds for maintenance: This problem was ranked second by the staff and third by students. Thus both staff and students agreed that sufficient funds are not often provided for maintenance by the University.

3. Lack of timely response to maintenance request: This problem was ranked third by staff respondents and second by student respondents with a mean of 4.23 and 3.98 for both staff and student respondents respectively. This shows that both staff and students believe that the work service department responds slowly to their maintenance request.

4. Poor maintenance work done by the maintenance unit of the institution: This problem was ranked fourth by staff and seventh by students with respective mean scores of 3.68 for staff respondents and 3.79 for student respondents. It also got a standard deviation of 1.33 and 1.24 for both staff and student respondents, respectively.

5. Corruption: Staff ranked this problem fifth while students ranked it second. The respective mean scores are 3.67 and 3.91. There is a noticeable disparity in the ranking by the two groups of respondents. Most maintenance works are not carried out in public institutions in Nigeria as a result of corruption. Thus, funds meant for maintenance work are embezzled by the authorities in-charge.

6. Lack of experienced and well trained building maintenance Engineer: This problem was ranked sixth by both staff and students with respective mean scores of 3.27 and 3.54. There is $100 \%$ ranking agreement by both groups of respondents.

7. Misuse of facilities by occupants: This problem was ranked seventh by the staff and fourth by students with respective mean scores of 2.97 and 3.82 . Moreover, the average score by staff indicates that they do not see this factor as significant $o$ an average level.

8. Change of government: This problem was ranked eighth by staff and fifth by students. The respective mean scores are 2.87 and 3.33. Also the staff do not see the factor to be of significance.

9. Poor architectural/structural design: Staff both ranked this problem ninth. The respective mean scores are 2.37 and 3.32, and staff do not see the problem as significant to an average level.

10. Overcrowding: This problem was rated $10^{\text {th }}$ by both the staff and students, with mean scores of 2.60 and 3.72 respectively. The staff do not see the problem to be significant up to average level.

\subsection{Condition of Buildings by Parts}

This section discusses the conditions of different parts of the buildings in the university. The conditions of different parts of the buildings in the university are indicative of the overall structural health of the buildings. Ninety percent of the buildings within the university (including residential buildings, hostels, offices, classrooms, University Secondary School and University Primary School) were surveyed and records of their conditions obtained, using the questionnaire and interview with the occupants.

Figures $2-9$ show the summary of conditions of the foundation, roof, floor, wall, painting, windows, doors, toilet and sewage facilities respectively, for the different types of buildings in the university.

\subsection{Staff Residential Houses}

\subsubsection{Foundation}

This is a very important part of a building. The foundation carries the load of the entire building and transfers it to the soil. From the survey conducted, $29.3 \%$ of the buildings had cracked foundation, $20 \%$ had weak foundation while $50.6 \%$ were in good condition. This means that about $49.3 \%$ of the staff residential buildings have problems with their foundations. This indicates that buildings needs urgent attention.

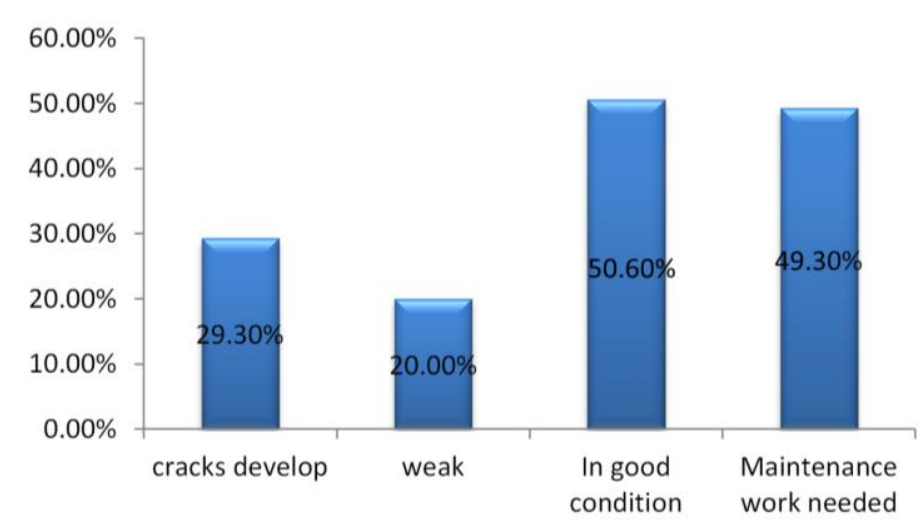

Fig. 1: Condition of foundation 


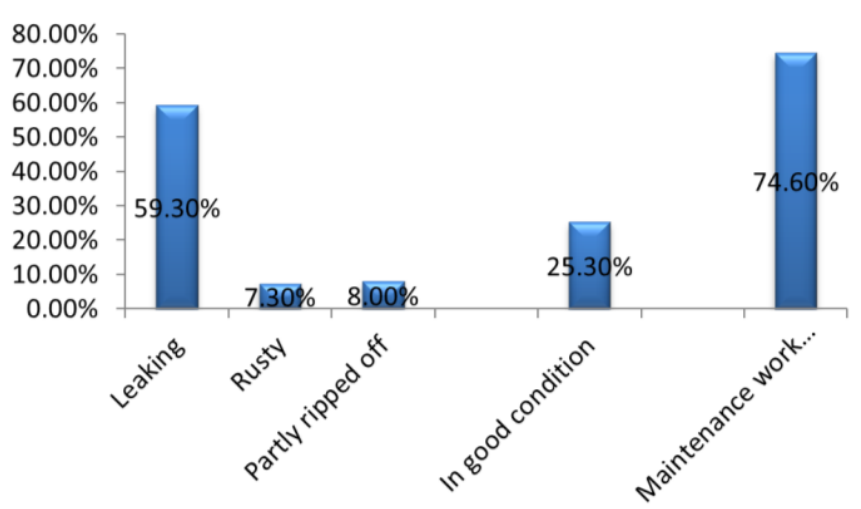

Fig.2: Condition of roof

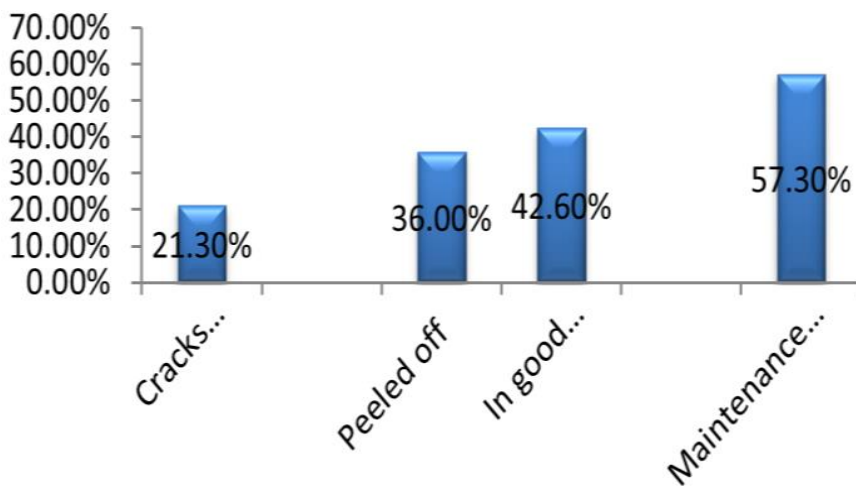

Fig.3: Condition of floor

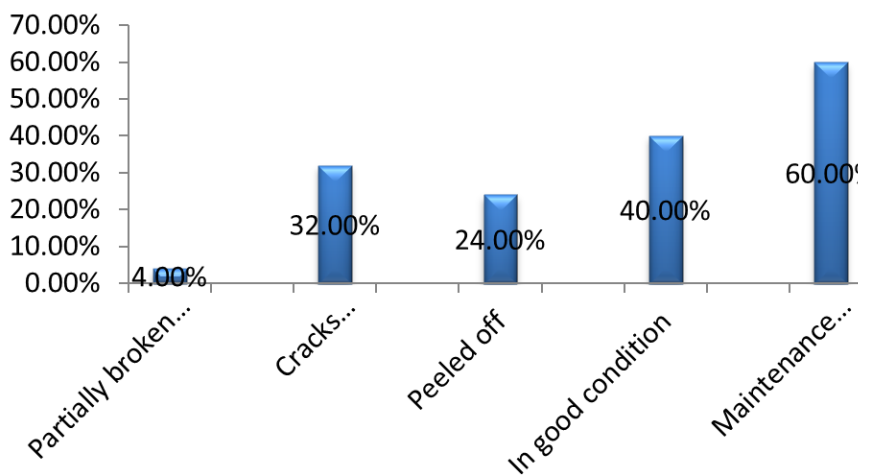

Fig.4: Condition of Wall

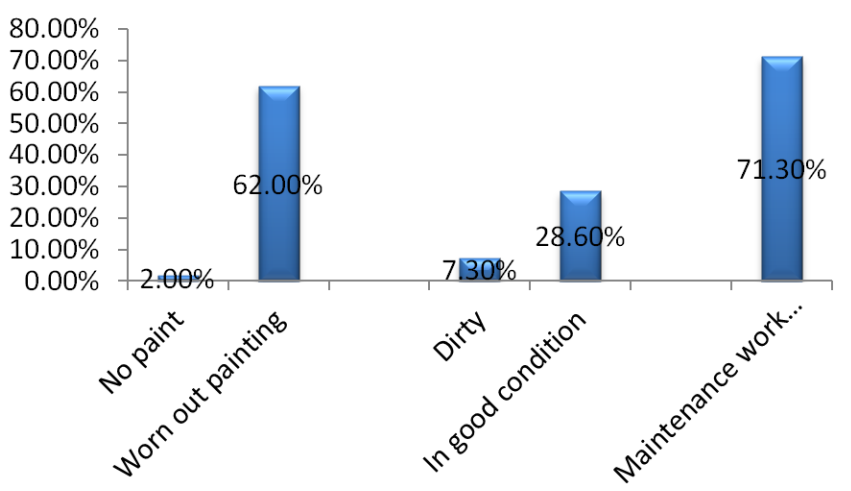

Fig.5: Condition of paint

\subsubsection{Roof}

The roof is a very important part of a building, it shelters the occupants from rain, sun and other environmental effects. From the survey conducted, it was discovered that $59.3 \%$ of the residential buildings in UNN have leaking roof, $7.3 \%$ have rusty roof, $8 \%$ of the roofs are partly ripped off while only $25.3 \%$ are in good condition. This means that $74.6 \%$ of the roofs need urgent attention for maintenance.

\subsubsection{Floor}

This is the part of the building that experience the most activity, occupants walk on the floor and heavy moveable loads are stationed to stand on the floor on a particular spot for a long time without repositioning, all these causes wearing of the floor. From the analysis of survey results, $21.3 \%$ of the residential buildings have cracked floors, while $36 \%$ have peeled off floors, only $42.6 \%$ had their floors in good condition. This means that $57.3 \%$ of the floors in residential buildings are in very bad condition and needs urgent maintenance. Most of the occupants noted that due to the bad condition of the floor of their building, they conducted self-maintenance on the floors by tiling the floor.

\subsubsection{Wall}

This is a very important part of a building, the wall partitions a building and gives the building a meaning. From the survey results $4.3,4 \%$ of the residential buildings have their walls partially broken down, 32\% have cracked walls, $24 \%$ have peeled off walls, while only $40 \%$ have their walls in good condition. This means that $60 \%$ of the walls of residential buildings in the university need maintenance.

\subsubsection{Paint}

Painting adds beauty to a building, and it also helps to protect the building against harsh weather. From analysis of survey conducted in table $4.3,2 \%$ of residential building in the university have no painting, $62 \%$ have worn out painting, $7.3 \%$ have dirty paint while only $28.6 \%$ have their painting still in good condition. This means that $71.3 \%$ of the residential buildings in the university needs urgent re-painting.

\subsubsection{Windows}

This element of a building helps to regulate the amount of air and sunlight that penetrates into a building. It also helps to protect the property of the occupants. From the survey conducted in table $4.3,14 \%$ of the residential buildings have their windows completely broken down, $54.6 \%$ have their windows partially 
broken down, while only $31.3 \%$ have their windows still in good condition. This means that $68.6 \%$ of the residential buildings surveyed need to have their windows replaced.

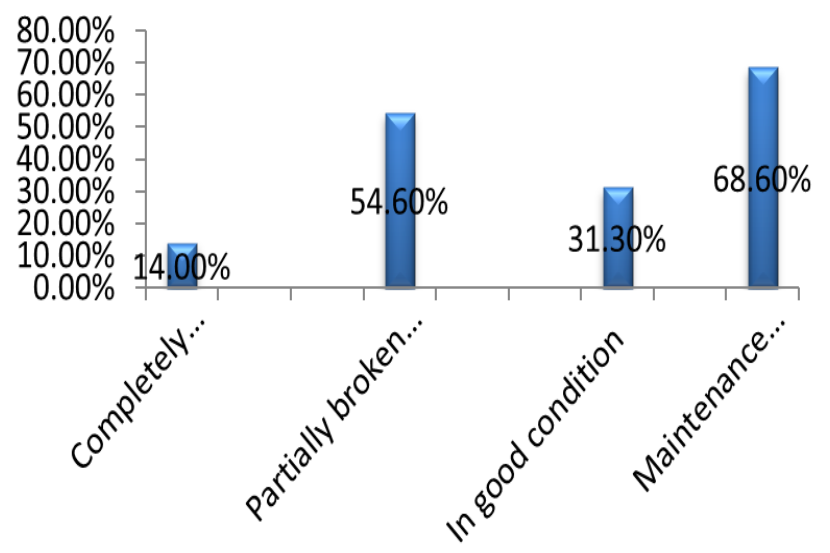

Fig.6: Condition of window

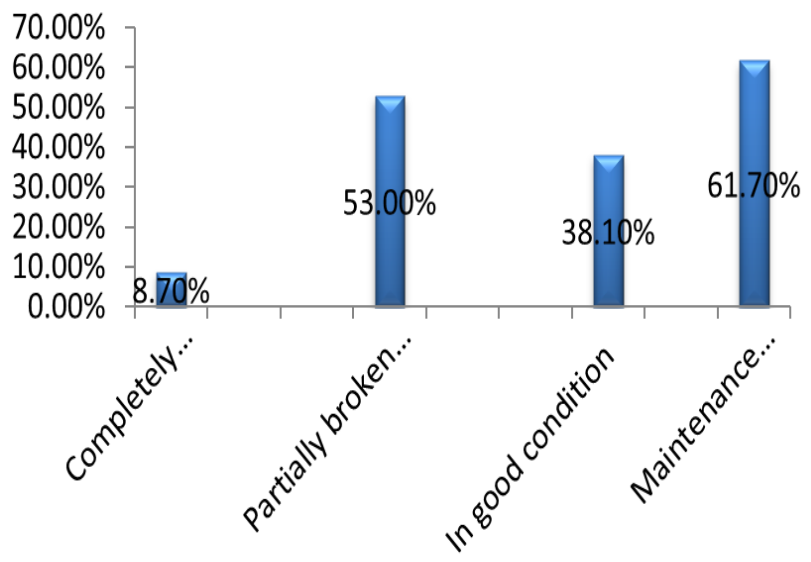

Fig.7: Condition of doors

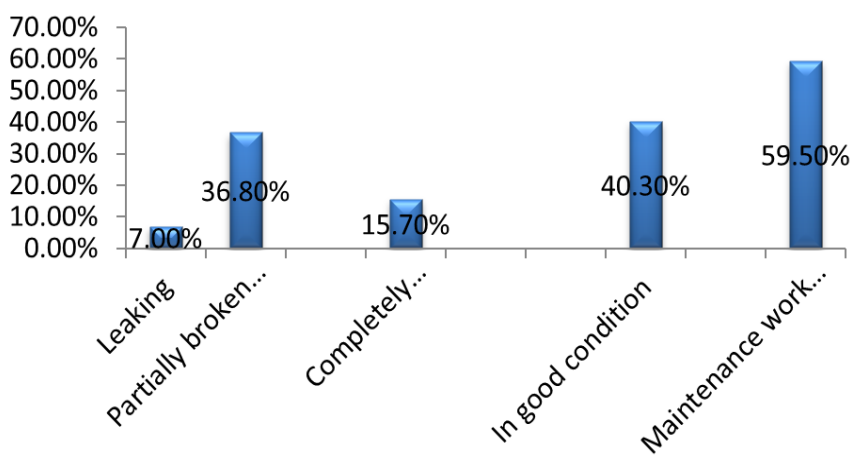

Fig. 8: Condition of toilet facilities

\subsection{Students Hostels}

\subsubsection{Doors}

$8.7 \%$ of the hostels have their doors completely broken down, $53 \%$ have partially broken down doors, while only $38.1 \%$ of the hostels still have their doors in good condition. This means that $61.7 \%$ of the hostels need to have their door fixed.

\subsubsection{Toilet Facilities}

$7 \%$ of the hostels have leaking toilet facilities, $36.8 \%$ have partially broken down toilet facilities, $15.7 \%$ have completely broken down toilet facilities, while only 40.3\% have their toilet facilities still in good condition. This means that $59.5 \%$ of the hostels need their toilets maintained.

\subsubsection{Sewage System}

$17.1 \%$ of the hostels have leaking sewage system, $23.2 \%$ have completely broken down sewage system, $32.1 \%$ have partially broken sewage system while $27.6 \%$ have their sewage system still in good condition. This means that $72.4 \%$ of the hostels need their sewage system maintained.

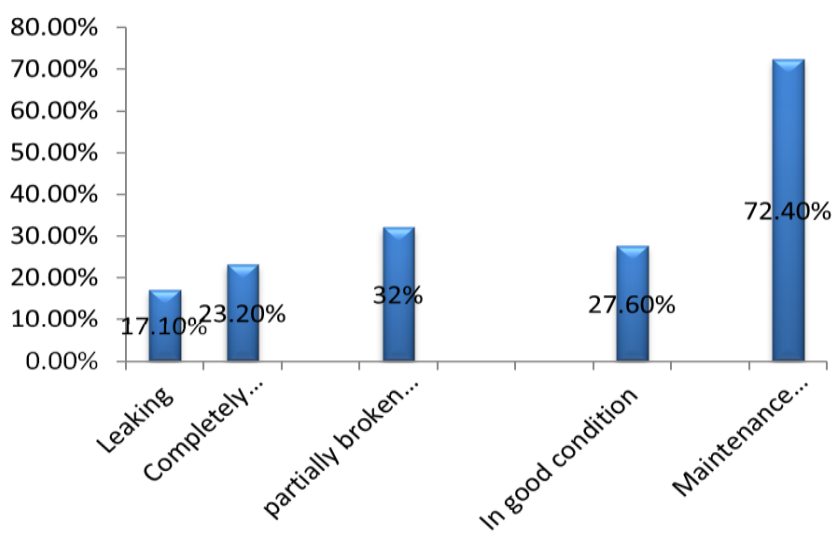

Fig. 9: Condition of sewage facilities

\section{CONCLUSION}

This research work investigated infrastructural maintenance in public institutions using UNN as a case study. This study found that about $80 \%$ of the building in University of Nigeria, Nsukka, requires one or more maintenance work.

According to this study, infrastructural maintenance is a big problem in public institutions in Nigeria. This is because maintenance plans are not integrated into the current project delivery process (i.e. planning, design, construction, operation and use). Thus, the project after completion is left without regular maintenance and this leads to severe infrastructural decay. This has ripple effects on the structural health and functional integrity of the infrastructure system.

The problems that militate against maintenance include; lack of maintenance policy, inadequate provision of funds for maintenance, poor execution of maintenance work by designated responsible units/agencies, corruption, lack of experienced staff (human capacity building), misuse of facilities by occupants, and poor architectural drawings/designs. 
For the staff residential buildings and students' hostels, maintenance works are needed at sewage systems, bathrooms, toilets, plumbing/water pipes, doors, windows, painting, walls, floors and roofs. Some of the staff residential buildings and students hostels have leaking sewage systems, broken down/leaking bathroom and toilet facilities, leaking water pipes, broken down doors, windows, worn out painting, cracked walls and floors, leaking roofs.

However, it was observed that not all the staff residential buildings are badly dilapidated. This is because some staff occupying the residential buildings conduct regular self-maintenance of the floors of their buildings by tiling. It demonstrates that a resultoriented maintenance culture instituted at both individual and organizational levels will positively impact on overall sustainable infrastructure delivery. The most common maintenance problems which occurred in the offices and classrooms are worn out paint, broken down toilets facilities, broken down electrical installations, leaking of roofs, broken windows and sewage systems. Most of the offices and classroom in the university have worn out paint, leaking/bad toilets, bad electrical installations, leaking roof, broken windows and leaking sewage system.

There is need for purpose-driven preventive maintenance culture and underpinning plans/policies as part of a holistic integrated infrastructure delivery process. Maintenance of infrastructure systems could also be outsourced.

\section{REFERENCES}

[1] Cobbinah, P. J.; Maintenance of Buildings of Public Institutions in Ghana, Case Study of Selected Institutions in the Ashanti Region of Ghana, M.Sc. Thesis, Kwame Nkrumah University of Science and Technology, Kumasi, Ghana, 2010.

[2] Adenuga, O. A , Odusami, K. I and Faremi, J. O, Assessment of factors affecting maintenance management of public hospital buildings in Lagos state, Nigeria. Department of Building, Faculty of Environmental science, University of Lagos, Nigeria, 2006.

[3] British standard institution (BS 3811): Glossary of maintenance management terms in technology, London, 1984.

[4] Ugwu, 0. 0. and Attah, I. C. "An appraisal of Construction Management in Nigeria, Nigerian Journal of Technology, Vol. 35, No. 4, pp. 754 $760,2016$.

[5] Oyigbo, T. E. and Ugwu, 0. 0. "Appraisal of key performance indicators on road infrastructure financed by Public Private Partnerships in Nigeria, Nigerian Journal of Technology, Vol. 36, No. 4, pp 1049 - 1058, 2017.

\section{APPENDIX: MAINTENANCE OF PUBLIC BUILDING.}

To be answered by residents of the building.

1. Name of street
2. Type of building (a) Bungalow
(b) Storey Building
(c) Flat

3. How long have you lived in the building?

4. How many Bedrooms, sitting rooms, Dining rooms, Kitchens, Toilets, Bathrooms, Garage are in the building?

5. Did you take inventory of the state of the facilities in the building before taking occupancy? YES NO

Give reasons for your response below.

Do you pay any rent for the building? YES
If yes, how much do you pay?
If no, give reason why you don't pay rent

6. Does the school maintenance personnel or unit conduct regular inspection of the building? YES If yes, is the maintenance conducted (a) Quarterly (b) Annually (c) Biannually? If no, give reasons why

7. Do you conduct regular self-maintenance of the building? YES $\square$ NO If yes, is the maintenance conducted (a) Quarterly (b) Annually (c) Biannually. If you conduct regular self-maintenance of your building, how much do you spend? 
If no, give reasons why you don't conduct regular self-maintenance of your building.

8. How long does it take the Works services Department to respond to maintenance request?

9. In your view is the building well maintained/in good condition? YES Please give reasons for your answer above

10. What are the reasons/factors responsible for the present condition of your building?

11. In what ways does the present condition of your building affect your lifestyle and living condition? What role do you play in the maintenance of your building?

MAINTENANCE OF BUILDING BY PARTS.

1. How can you describe the condition of your building foundation? (a) Cracks developed

(b) Weak (c) In good condition.

2. How can you describe the condition of your roof ? (a) leaking (b) Rusty (c) Partly ripped off.

3. How can you describe the condition of your floor? (a) Cracks developed (b) peeled off (c) In good condition.

4. How can you describe the condition of your wall? (a) partially broken down (b) Cracks developed (c) peeled off (d) Bent (e) In good condition.

5. How can you describe the painting condition? (a) No painting (b) Worn out painting (c) dirty (d) In good condition.

6. How can you describe the condition of your windows? (a) broken down (b) partially broken down (c) In good condition.

7. How can you describe the conditions of your doors? (a) broken down (b) partially broken down (c) In good condition.

8. How can you describe the condition of your electrical installations? (a) partially functioning (b) completely broken down (c) In good condition.

9. How can you describe the condition of plumbing/water pipe? (a) Leaking (b) partially broken down (c) Completely broken down (d) In good condition.

10. What type of toilet facility do you use? (a) Water System (b) pit latrine, if any other, please specify

11. Are the toilet facility (a) Leaking (b) partially broken down (c) completely broken down (d) In good condition.

12. How can you describe the condition of your kitchen? (a) Well ventilated (b) poorly ventilated (c) No ventilation (d) No kitchen at all

13. How can you describe the condition of your kitchen facility? (a) Leaking (b) broken down (c) partially broken down (d) In good condition (e ) No kitchen at all

14. How can you describe the condition of your bathroom facility (a) Leaking (b) broken down

(c) partially broken down (d) In good condition.

15. Do you have provision for bathroom shower?

If yes, is it still functioning? YES $\square$ NO

16. How can you describe the condition of your sewage system? (a) Leaking (b) broken down

(c) partially broken down (d) In good condition.

Below are some of the major problems/factors that affect public building maintenance. In your opinion kindly rate each of these selected factors in terms of their weight as they affect public building maintenance in Nigeria. The weights (on a Likert Scale of 1-5) are enclosed in brackets. 
Table 2 Factors Affecting Maintenance of Public Buildings

\begin{tabular}{|c|c|c|c|c|c|c|}
\hline $\mathrm{S} / \mathrm{N}$ & Factor & $\begin{array}{c}\text { Very } \\
\text { significant } \\
(5)\end{array}$ & $\begin{array}{c}\text { Significant } \\
\text { (4) }\end{array}$ & $\begin{array}{c}\text { Average } \\
\text { significant } \\
(3) \\
\end{array}$ & $\begin{array}{c}\text { Little } \\
\text { significant } \\
(2)\end{array}$ & $\begin{array}{l}\text { Not } \\
\text { Significant } \\
\text { at all (1) }\end{array}$ \\
\hline 1 & Lack of maintenance policy & & & & & \\
\hline 2 & $\begin{array}{l}\text { Inadequate provision of funds for } \\
\text { maintenance }\end{array}$ & & & & & \\
\hline 3 & $\begin{array}{l}\text { Lack of experienced and well } \\
\text { trained building maintenance } \\
\text { Engineer }\end{array}$ & & & & & \\
\hline 4 & Overcrowding & & & & & \\
\hline 5 & $\begin{array}{l}\text { Lack of timely response to } \\
\text { maintenance request }\end{array}$ & & & & & \\
\hline 6 & $\begin{array}{l}\text { Poor maintenance work done by } \\
\text { the maintenance unit of the } \\
\text { institution }\end{array}$ & & & & & \\
\hline 7 & Corruption & & & & & \\
\hline 8 & Misuse of facilities by occupants & & & & & \\
\hline 9 & $\begin{array}{l}\text { Poor architectural/structural } \\
\text { design }\end{array}$ & & & & & \\
\hline 10 & Change of government & & & & & \\
\hline
\end{tabular}

17. Please describe the general state of your building presently (a) good (b) fairly good (c) bad (d) Very bad. 